\title{
CORROSION RATE AND CORROSION BEHAVIOUR ANALYSIS OF CARBON STEEL PIPE AT CONSTANT CONDENSED FLUID
}

\author{
Ahmad Royani *, Siska Prifiharni, Gadang Priyotomo, Sundjono Sundjono \\ Research Center for Metallurgy and Materials - Indonesian Institute of Sciences, \\ Indonesia
}

Received 30.11.2020

Accepted 17.04.2021

\begin{abstract}
This study investigates the corrosion rate and corrosion behavior of carbon steel pipe at constant condensed fluid from a geothermal power plant. The corrosion rate of the steel was determined by weight loss analysis, whereas the corrosivity of the condensate fluids was measured by a multimeter Hach HQ40d. The morphology of the corrosion products formed was characterized by scanning electron microscopy (SEM), energy dispersive spectrometry (EDS), and x-ray diffraction (XRD) analysis. Results showed that the corrosion rate in the liquid part of the condensate fluids is constant during the immersion period when water quality parameters are constant. Meanwhile, the corrosion rate of low carbon steel pipe decreases though with the longer exposure period in the condensate fluid. The decrease of metal corrodibility identical to the lower corrosion rate at a longer exposure time due to the protective corrosion layer formed. The corrosion products during immersion tests identified in the corrosion test were uniform with iron oxide in the form of $\mathrm{FeO}(\mathrm{OH})$ and $\mathrm{Fe}_{2} \mathrm{O}_{3} \cdot \mathrm{H}_{2} \mathrm{O}$.
\end{abstract}

Keywords: Condensate, corrosion, immersion, steel pipe, weight loss analysis.

\section{Introduction}

The main problems in condensate pipeline systems in geothermal power plants include corrosion, deposits, and slime formation [1]. Corrosion can shorten the service life of the material pipeline because it results in reduced operating efficiency, leakage, and pollution [2]. Deposits and slime, in addition to reducing heat efficiency in heat exchangers and pipeline systems, can also cause localized corrosion i.e, corrosion under the deposit due to differences in oxygen concentration [3]. These problems can occur in very complex systems with many contributing factors.

On the other, the water source in condensate pipeline systems can come from groundwater, lakes, rivers, and seawater [4]. In general, the raw water contains suspended solids and dissolved ions which can cause corrosion or deposits. Also,

"Corresponding author: Ahmad Royani, ahmad.royani@lipi.go.id 
cooling water in open and one-cycle recirculation systems is usually contaminated with several solutes, suspended solids, and microorganisms. Therefore, the formation of deposits, the occurrence of corrosion, and the formation of slime were happened in open and one-turn recirculation systems [5]. One of the factors that influence the formation of corrosion and deposits (scale) in the cooling system is the chemical composition of the fluid. Other critical parameters for fluid properties include temperature [6], velocity [7], conductivity, total dissolved solids (TDS), hardness, $\mathrm{pH}$, alkalinity, and saturation index $[8]$.

Carbon steel is widely used in pipeline systems in the oil and gas industry. Carbon steel is used mainly in cooling water lines and heat exchanger units in closed and open recirculating systems [9]. Therefore, it is important to understand the corrosion behavior of these materials due to contact with fluids in the cooling system. Internal corrosion in condensate pipelines is primarily caused by the presence of water together with acid gases [10] or dissolved solids [11]. Corrosion degradation of pipeline carbon steels subjected to aggressive condensed brines was reported [12]. The carbon steel is subjected to hydrogen embrittlement due to the $\mathrm{H}^{+}$reduction during the corrosion process in brines. M. Islami et al. [13] reported the influence of surface temperature on the corrosion rate of carbon steel in water condensed. This author mentioned that the surface temperature mainly governs the corrosion of carbon steel at low temperatures. However, at moderate surface temperatures, the corrosion rate was affected by surface temperature and water condensation rate [13].

In this study, the carbon steel pipe from a condensate pipeline in a geothermal power plant was the subject of an immersion test carried out in condensed fluids according to ASTM G-31 standard [14]. The study aimed to determine the corrosion performance of carbon steel pipe in a condensed environment, study the corrosivity of the condensed fluids and the corrosion rates of the carbon steel with the exposure time. The outcome of this study is to map a guideline for the application of carbon steel in a corrosive environment, especially in the condensed fluid environment.

\section{Experiment}

The specimens of carbon steel pipe and condensated fluids from a geothermal power plant were used in this study. The chemical composition of the carbon steel pipe specimen can be seen in Table 1 with microstructure as specified in Fig. 1. While for the water quality parameters of condensate fluids are presented in Table 2.

Table 1. The chemical composition of a specimen steel pipe.

\begin{tabular}{lll}
\hline $\begin{array}{l}\text { Element } \\
\text { (\% wt. })\end{array}$ & Name of Material & \\
\cline { 2 - 3 } $\mathrm{Fe}$ & Specimen pipe & API 5L Gr B \\
$\mathrm{C}$ & Balance & Balance \\
$\mathrm{Mn}$ & 0.0802 & $0.22 \mathrm{max}$ \\
$\mathrm{Si}$ & 1.1086 & 1.28 \\
$\mathrm{~S}$ & 0.2572 & 0.45 \\
$\mathrm{P}$ & 0.0035 & 0.03 \\
\hline
\end{tabular}




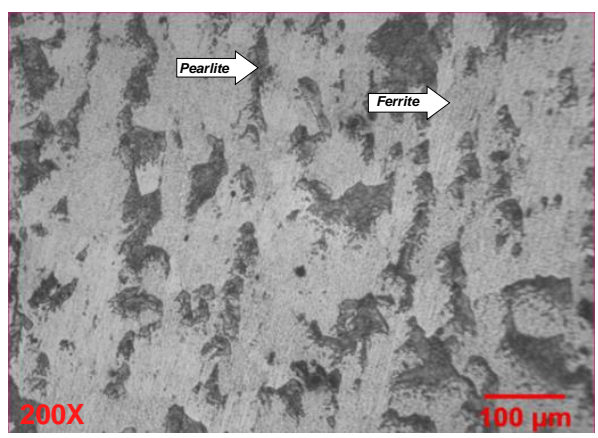

Fig. 1. The microstructure of low carbon steel pipe.

Table 2. The chemical composition of the condensate fluids.

\begin{tabular}{lll}
\hline Parameter & Unit & Value \\
\hline Calcium Hardness & $\mathrm{ppm}$ & 1 \\
Total Alkalinity & $\mathrm{ppm}$ & 3.7 \\
$\mathrm{pH}$ & - & 5.63 \\
Temp. & ${ }^{\circ} \mathrm{C}$ & 28 \\
Salinity & $\mathrm{ppt}$ & 0.12 \\
Conductivity & $\mu \mathrm{s} / \mathrm{cm}$ & 254 \\
Dissolved solids & $\mathrm{ppm}$ & 121 \\
\hline
\end{tabular}

The steel pipe was cut with dimensions of $70 \mathrm{~mm} \times 20 \mathrm{~mm} \times 2 \mathrm{~mm}$, then it was marked, and then perforated on the top end. Before the immersion test, the surface of the specimen was cleaned according to ASTM G-1 standards [15]. After surface cleaning, the specimens were weighed using analytical scales and then stored in a desiccator.

The immersion test was carried out by inserting the specimen into a reactor glass at a certain time in the water batch. Adjust the water level, and then after the target temperature was achieved, the quality parameters of the solution were measured with a sensor probe (Multi-Meter HQ40d). If target conditions were reached, the specimen was put into the solution by hanging the specimen in the holder using a string. Then, the reactor glass was closed and left for a certain exposure time. The method used in this immersion test is referred to as the planned interval test method. The design of the interval test is illustrated in Table 3. Two specimens were used for each test in this work.

Table 3. The design of the planned interval test.

\begin{tabular}{lllll}
\hline \multirow{2}{*}{ No } & \multirow{2}{*}{ Code } & \multicolumn{2}{l}{ Period (monthly) } & \multirow{2}{*}{ Exposure time (days) } \\
\cline { 3 - 4 } & In & Out & 28 \\
1 & A1 & 0 & 1 & 84 \\
2 & A3 & 0 & 3 & 112 \\
3 & A4 & 0 & 4 & 28 \\
4 & B & 3 & 4 &
\end{tabular}


After the immersion test, the specimen was cleaned according to the ASTM G-1 standard [15]. The method for determining the corrosion rate based on weight loss follows the equation:

$$
\text { Corr. Rate }=3.45 \times 10^{6}\left(\frac{W}{D A T}\right)
$$

W: weight loss (grams); D: steel density $\left(\mathrm{g} / \mathrm{cm}^{3}\right)$; A: area $\left(\mathrm{cm}^{2}\right)$; and T: exposure time (hours).

Measurement of the quality of the condensed fluid is done by using a portable multimeter Hach (HQ40d). The parameters measured were solution temperature, salinity, the content of dissolved oxygen (DO), conductivity, TDS (total dissolved solids), and $\mathrm{pH}$. The measurement of the quality of the test media was carried out periodically.

The morphology of the corrosion products from the surface specimen was observed using scanning electron microscopy (JEOL JSM-6390A) and energy dispersive spectrometry (EDS). The corrosion product compounds were analyzed using X-ray diffraction (Shimadzu XRD 7000).

\section{Results and Discussion}

Based on the chemical composition results, the carbon steel pipe specimen was identical to the API 5L Grade B steel as seen in Table 1. The corrosion rate results for low carbon steel pipe versus exposure time are presented in Fig. 2. From data of the corrosion rate in Fig. 2, it can be seen that the corrosion rate is very similar. These results indicate that the corrosion rate in the condensed fluids is constant during the testing period. The result of the difference of corrosion rate in the fourth (A4) and third (A3) months is less than the corrosion rate in the last month (B), indicating that the corrosion rate of the specimen tends to decrease.

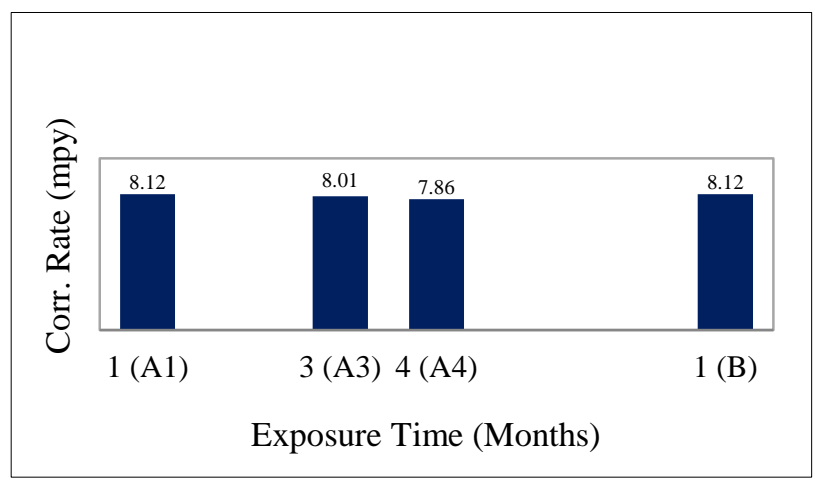

Fig. 2. Corrosion rate versus exposure time.

The reduced corrosion rate of the carbon steel could be due to the reduced contact area between the carbon steel surface and the condensed fluid when the corrosion product is formed. The presence of a corrosion product layer on the metal 
surface can inhibit the diffusion of a corrosive species towards the carbon steel surface; hence the corrosion rate decreases with the time of exposure [16].

Based on the corrosion rate obtained from the immersion test, the corrosion performance of the specimen in this study was assigned to the poor category as the classification in Table 4. During the immersion of the specimen, some transient state can occur both on the steel specimen and in the test solution. Changes in test conditions during the immersion process with the planned-interval test and effect on corrosion rate are described in Table 5.

Table 4. The category of corrosion rate for steel in the open recirculating system [8].

\begin{tabular}{ll}
\hline Corrosion rate (mpy) & Category \\
\hline$\leq 1$ & Excellent \\
$1-3$ & Very good \\
$3-5$ & Good \\
$5-8$ & Moderate \\
$8-10$ & Poor \\
$>10$ & Very poor \\
\hline
\end{tabular}

Table 5. The criteria of the planned-interval test [17].

\begin{tabular}{llll}
\hline No & Liquid corrosiveness & Metal Corrodibility & Criteria \\
\hline 1 & Unchanged & Unchanged & A1 $=$ A2 $=$ B \\
2 & Unchanged & Decreased & A2 $<$ B $=$ A1 \\
3 & Unchanged & Increased & A1 $=$ B $<$ A2 \\
4 & Decreased & Unchanged & A2 $=$ B $<$ A1 \\
5 & Decreased & Decreased & A2 B $<$ A1 \\
6 & Decreased & Increased & A1 $>$ B $<$ A2 \\
7 & Increased & Unchanged & A1 $<$ A2 $=$ B \\
8 & Increased & Decreased & A1 $<>$ A2 \\
9 & Increased & Increased & A1 $<$ B $<2$ \\
\hline
\end{tabular}

The corrosion rate of steel depends on several parameters such as the chemical composition of the steel [18], the surface roughness of the steel [19], and the environment such as water properties [20]. Water properties include temperature, salinity, the content of dissolved oxygen (DO), conductivity, TDS (total dissolved solids), and $\mathrm{pH}[21]$.

One of the water properties or the condensed fluid property that affects the liquid corrosivity is the temperature. In general, the temperature can increase the corrosion rate exponentially with an increased temperature of $10{ }^{\circ} \mathrm{C}$. The corrosion rate can, for instance, be multiplied when the temperature of the water rises [22]. The measurement results of the temperature condensed fluid are presented in Fig. 3. In this study, the temperature of the condensed fluid was kept constant at $50{ }^{\circ} \mathrm{C}$ and did not alter significantly.

The liquid corrosivity is not only influenced by temperature but also influenced by other parameters. One of those parameters is chloride content in the fluid. The chloride content in water is defined as salinity [4]. Therefore, salinity is predicted by determining the concentration of $\mathrm{Cl}^{-}$ions in water. The empirical correlation between salinity and $\mathrm{Cl}^{-}$ion content is formulated in equation [5]: 


\section{$1.80655 \times\left[\mathrm{Cl}^{-}\right]$}

The salinity measurement results from the immersion test are presented in Fig. 4. The salinity obtained was relatively the same and the value was very small, between $0.09 \mathrm{ppt}$ and $0.10 \mathrm{ppt}$. These results indicate that the condensate fluid is categorized as fresh water because the content of chloride ions is below $1000 \mathrm{ppm}$ [5].

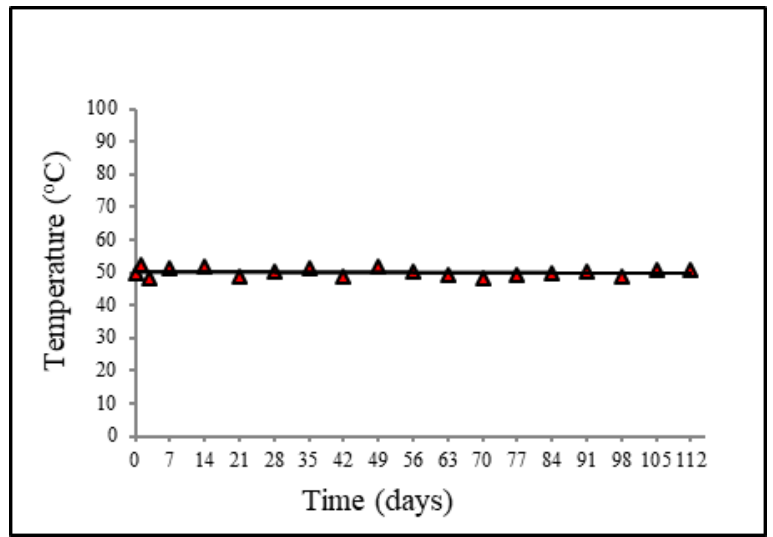

Fig. 3. The result of temperature solution versus exposure time.

The liquid corrosivity of natural water increases proportionally if the value of salinity increases [23]. If salinity exceeds $3 \%$ however, water corrosivity will decrease [24]. Otherwise, the higher the salinity, the lower the oxygen solubility [25]. Thus, with salinity above $3 \%$, the rate of corrosion in the water decreases. Likewise, if salinity is very small, the effect is very small on the corrosion rate.

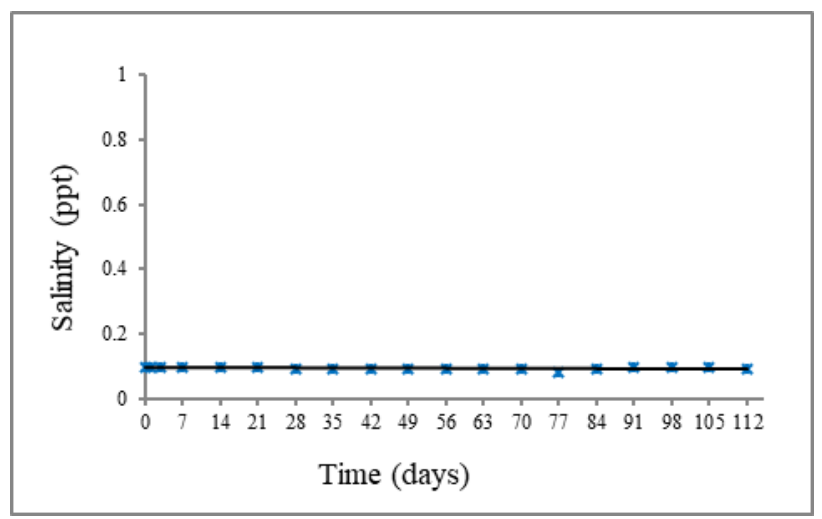

Fig. 4. The result of salinity versus exposure time.

Another water quality parameter that affects the corrosion rate in the condensed fluid is the content of dissolved gas. The dissolved gas that affects the corrosivity of the 
solution in the corrosion aspect is oxygen and carbon dioxide [26]. The solubility of oxygen and carbon dioxide in the fluid decreases with increasing temperature and salinity [27]. Oxygen acts as a depolarizer in the cathode and increases the extent of the corrosion process [17]. The results of dissolved oxygen (DO) measurements versus immersion time are shown in Fig. 5.

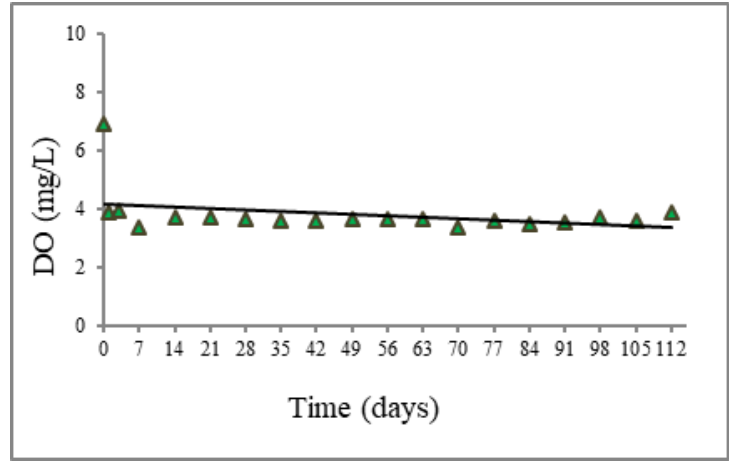

Fig. 5. The result of dissolved oxygen versus exposure time.

Based on the data in Fig. 5, it is evident that the effect of oxygen was reflected on the corrosion rate. DO values decreased in the condensate fluids after the specimen is exposed. In the beginning, the initiation process of corrosion began to occur in the anodic region so that oxygen consumption in the cathodic region increased. As a result of this event, oxygen dissolved in condensate fluid decreased. The mechanism of chemical reactions occurring in a neutral solution by the following reaction equation [24]:

At the anode area, iron $(\mathrm{Fe})$ oxidizes to iron ions $\left(\mathrm{Fe}^{2+}\right)$ :

$$
\mathrm{Fe} \rightarrow \mathrm{Fe}^{2+}+2 e^{-}
$$

whereas at the cathode, the reduction reaction of dissolved oxygen occurs:

$$
\mathrm{H}_{2} \mathrm{O}+1 / 2 \mathrm{O}_{2}+2 e^{-} \rightarrow 2 \mathrm{OH}^{-}
$$

The above reactions occur simultaneously and a variety of further reactions occur in the solution. In the corrosion process, iron ions $\left(\mathrm{Fe}^{2+}\right)$ formed at the anode will oxidize to be iron oxide in the form of a thin layer on the metal surface and prevent further iron corrosion processes:

$$
\mathrm{Fe}^{2+}+2^{e-}+1 / 2 \mathrm{O}_{2} \rightarrow \mathrm{FeO}
$$

Smilarly, at the cathode, oxygen must reach the metal surface for the reaction (4) to occur. The oxygen also oxidizes $\left(\mathrm{Fe}^{2+}\right)$ to $\left(\mathrm{Fe}^{3+}\right)$, so that rust $\left(\mathrm{Fe}_{2} \mathrm{O}_{3} \cdot \mathrm{H}_{2} \mathrm{O}\right)$ was formed. The rust was formed can be obtained by adding reaction (3) and (4):

$$
2 \mathrm{Fe}+2 \mathrm{H}_{2} \mathrm{O}+\mathrm{O}_{2} \rightarrow 2 \mathrm{Fe}^{2+}+4 \mathrm{OH}^{-} \rightarrow 2 \mathrm{Fe}(\mathrm{OH})_{2}
$$


However, this compound is unstable in oxygenated solutions and is oxidized to ferric salt (rust).

$$
2 \mathrm{Fe}(\mathrm{OH})_{2}+\mathrm{H}_{2} \mathrm{O}+1 / 2 \mathrm{O}_{2} \rightarrow \mathrm{Fe}_{2} \mathrm{O}_{3} * \mathrm{H}_{2} \mathrm{O}
$$

The corrosion rate of carbon steel pipe was affected significantly by dissolved oxygen in the solution. It was even reported that internal corrosion of water pipes can be prevented by reducing DO concentrations [26] and others reported that DO greatly affects the corrosion rate [28-31]. Liquid corrosivity is not only a function of dissolved oxygen but also influenced by other factors. These factors include the conductivity of the water [7], dissolved solids, and the acidity of the solution [32]. The results of the conductivity and TDS measurements of the condensed fluids at various exposure times have similar values as shown in Fig. 6 and Fig. 7. Those results show that the liquid corrosivity of the condensed fluid was constant as observed by the results of the corrosion rate in the first month (A1) and the last month (B). Theoretically, the corrosion rate of steel in water with high conductivity tends to be greater than in water with low conductivity [9].

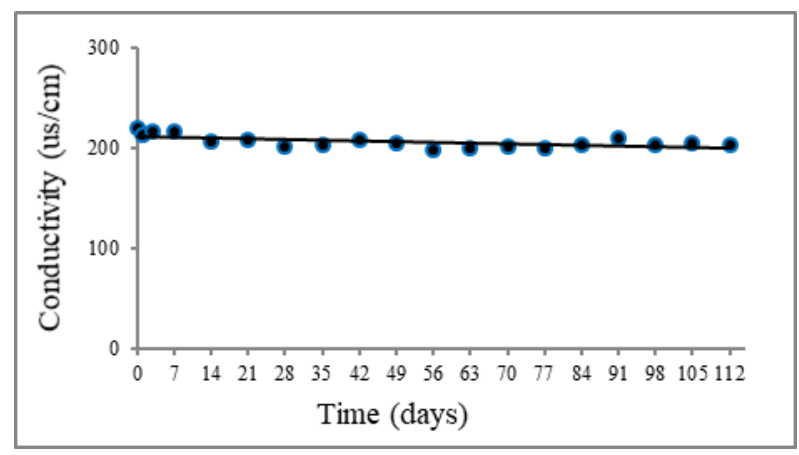

Fig. 6. The result of conductivity versus exposure time.

Conductivity and TDS were constant in this study has and hence no significant effect of conductivity and TDS on the corrosion rate occurred. However, total dissolved solids and high conductivity of the fluid can increase corrosion rate [11]. This relates to the conductivity of the exchange of ions at the cathode and the anode more such that the rate of mass transfer of ions occurs faster [33].

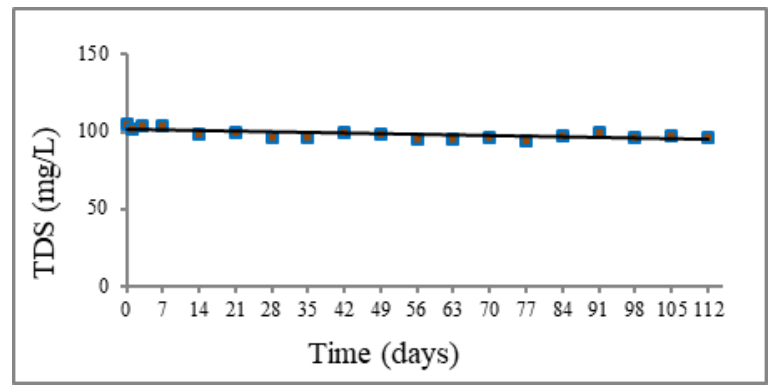

Fig. 7. The result of TDS versus exposure time. 
The measurement results of $\mathrm{pH}$ versus time are presented in Fig. 8. The $\mathrm{pH}$ value of the initial solution before testing was about 5. However, after 1 day the $\mathrm{pH}$ of the solution become around 7 and thereafter was relatively constant with exposure time. This is because the corrosion process has occurred through electrochemical reactions, so the acid concentration was reduced after exposure time. Based on the results of this $\mathrm{pH}$ measurement, the condensate fluid was categorized as a neutral environment that has little influence on the corrosion rate. However, a decrease in $\mathrm{pH}$ can make water more acidic and consequently the solution becomes more corrosive [7]. The effect of $\mathrm{pH}$ on the solubility of corrosion products during the corrosion process is often the key to understanding metal concentrations in the water environment [4].

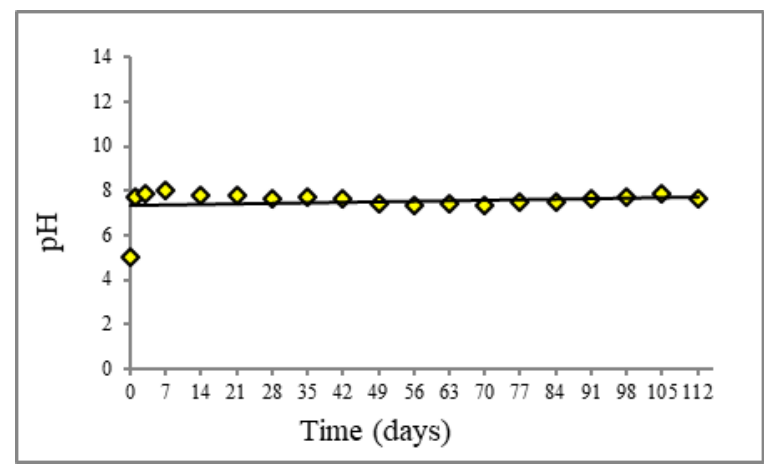

Fig. 8. The result of $\mathrm{pH}$ versus exposure time.

The water quality parameters of the solution not only affected liquid corrosivity and the corrosion rate of the metal. However, these parameters also affect the characteristics and morphology of corrosion products.

The visual and morphology of the corrosion products from low carbon steel pipe specimens are shown in Fig. 9 with EDS in Fig. 10. Carbon steel pipe reacts aggressively with dissolved oxygen in the water. The corrosion product is iron oxide hydrate. From Fig. 9, it can be seen the morphology and the forms of corrosion that uniform corrosion has occurred on the carbon steel surface.

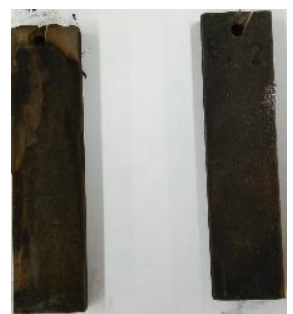

(a)

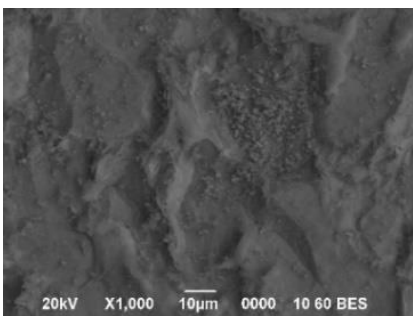

(b)

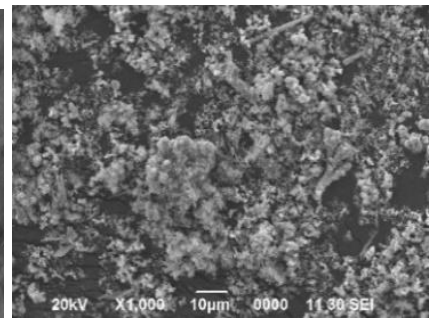

(c)

Fig. 9. The visual and morphology of corrosion products for low carbon steel pipe: a) visual, b) corrosion product on the surface metal, c) deposit of corrosion product in solution. 


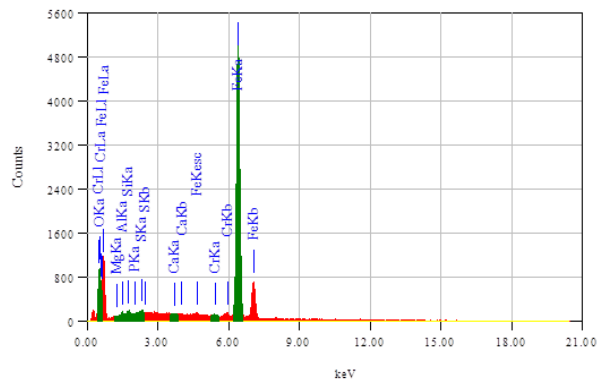

(a)

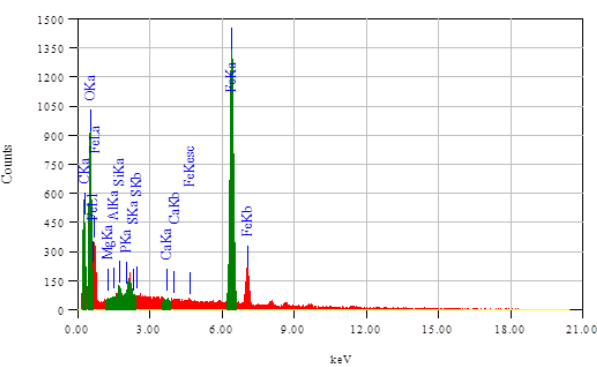

(b)

Fig. 10. The results of the EDS for corrosion product: a) corrosion product on the surface metal, $b$ ) deposit of corrosion product.

The results of SEM and EDS indicated qualitatively that the dominant elements in corrosion products were iron, carbon, and oxygen. The content of the chemical composition of corrosion products can be seen in Table 6 . The distribution of rust products covered all surfaces metal as shown in the result of SEM photos in Fig. 9.

Table 6. Elements in corrosion product.

\begin{tabular}{lllllllll}
\hline \multirow{2}{*}{ Sample } & \multicolumn{7}{c}{ Element (wt.\%) } \\
\cline { 2 - 9 } & $\mathrm{Fe}$ & $\mathrm{O}$ & $\mathrm{C}$ & $\mathrm{Si}$ & $\mathrm{Al}$ & $\mathrm{Cr}$ & $\mathrm{S}$ & $\mathrm{P}$ \\
\hline Surface & 93.04 & 5.76 & - & 0.18 & 0.41 & 0.36 & 0.20 & 0.04 \\
Deposit & 55.63 & 20.57 & 19.93 & 0.44 & 0.14 & - & - & - \\
\hline
\end{tabular}

The results of surface morphology and elemental content of the corrosion product have not predicted the corrosion product compound. Therefore, an analysis by using XRay diffraction was carried out to determine the corrosion product formula. The results of XRD on corrosion products are shown in Fig. 11.

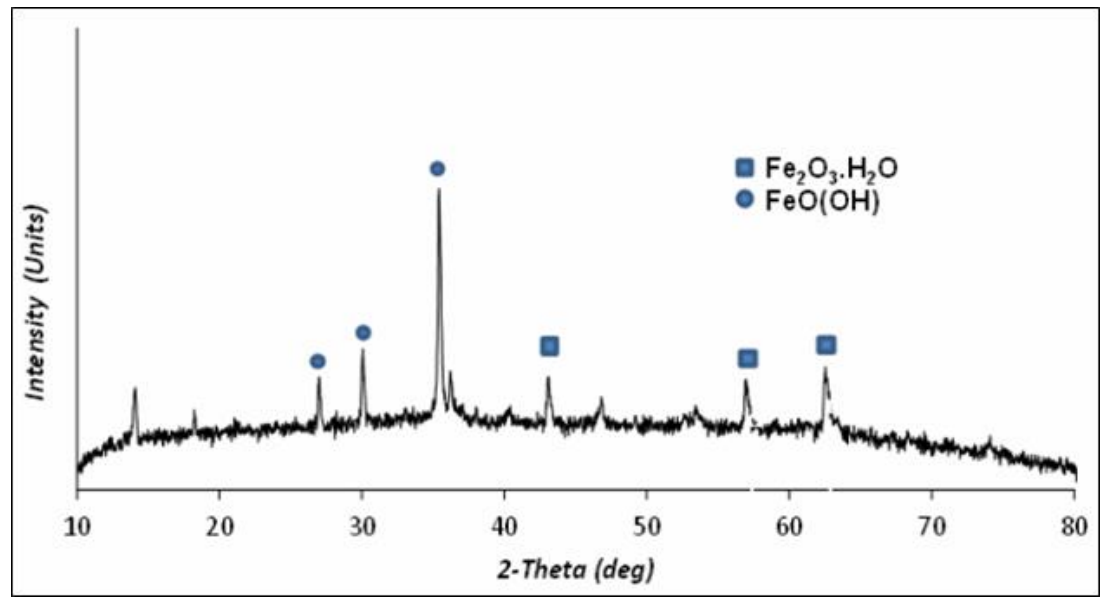

Fig. 11. X-ray diffraction patterns for corrosion products. 
The X-ray diffraction results of the experiment were matched with standard data diffractograms. The resulting matching obtained the oxides on the surface on carbon steel pipe are $\mathrm{FeO}(\mathrm{OH})$ and $\mathrm{Fe}_{2} \mathrm{O}_{3} \cdot \mathrm{H}_{2} \mathrm{O}$.

\section{Conclusions}

In this work, the corrosion rate and corrosion behavior of a carbon steel pipe were investigated in condensed fluid from a geothermal power plant. Results showed that the liquid corrosivity of the condensed fluid was constant during the immersion period with unchanged water quality parameters. Meanwhile, the corrosion rate of the low carbon steel pipe decreased with the length of exposure time in this condensate media. The decrease of the corrosion rate of the carbon steel was identical to the lower corrosion rate at a longer exposure time due to the layer a corrosion product formed. The corrosion products during immersion tests were uniform with iron oxide in the form of $\mathrm{FeO}(\mathrm{OH})$ and $\mathrm{Fe}_{2} \mathrm{O}_{3} \cdot \mathrm{H}_{2} \mathrm{O}$. The value of the corrosion performance is categorized in the poor criteria i.e high corrosion rate. These results aid in understanding the corrosion effect of the condensed fluid on the carbon steel pipelines and can therefore help to schedule maintenance plans for the in-situ pipelines before failure.

\section{Acknowledgments}

The author would like to thank the Research Center for Metallurgy and Materials, Indonesian Institute of Sciences, for corrosion laboratory supporting. Also, thanks to the geothermal power plant for material support in this work.

\section{References}

[1] K. Sakaguchi and V. Anbumozhi: Report 2014-14, ERIA Research, Jakarta, 2015.

[2] A. K. Sinha: AKS-Journal, 1 (2010) 1-20.

[3] Y. M. Al Rawahi, F. Shaik, and L. Rao, N: Int. J. Innov. Res. Sci. Technol., 3 (2017) 152-167.

[4] F. D. Owa: Mediterr. J. Soc. Sci., 4 (2013) 65-68.

[5] R. Pierre R: Corrosion Engineering: Principles and Practice, Mc Graw Hill, New York, 2008.

[6] Y. Chen, L. Zhang, H. Qin, L. Xu, and M. Lu: Corrosion, (2011) 13-17.

[7] H. Li, A. Shi, M. Li, and X. Zhang: J. Chem., 1 (2013) 1-12.

[8] E. R. Alley: Water Quality Control Handbook, Second ed., Mc Graw Hill, New York 2007.

[9] A. Royani, S. Prifiharni, G. Priyotomo, and Sundjono: Int. J. Mechatronics Appl. Mech., 2 (2020) 158-164.

[10] W. Zhao, T. Zhang, Y. Wang, J. Qiao, and Z. Wang: Materials (Basel)., 11 (2018) 1-17.

[11] Q. Cui, S. Chandra, and S. McCahan: J. Heat Transfer, 123 (2001) 719-728.

[12] C. Miranda-Herrera, I. Sauceda, J. González-Sánchez, and N. Acuña: AntiCorrosion Methods Mater., 57 (2010) 167-172.

[13] M. M. Islam, T. Pojtanabuntoeng, and R. Gubner: Corros. Sci., 111 (2016) 139150.

[14] ASTM International, "Standard Practice for Laboratory Immersion Corrosion Testing of Metals," in ASTM Special Technical Publication, vol. I, no. Reapproved, ASTM International, 1985, pp. 534-544. 
[15] ASTM International: Standard Practice for Preparing, Cleaning, and Evaluating Corrosion Test, in ASTM Special Technical Publication, ASTM International, 1999.

[16] A. Royani et al., in IOP Conference Series: Materials Science and Engineering, 541: 2019, 1-10.

[17] M. G. Fontana: Corrosion Engineering, Third ed., Mc Graw Hill, Singapore, 1987.

[18] D. Dwivedi, K. Lepková, and T. Becker: RSC Adv., 7 (2017) 4580-4610.

[19] S. D. Cramer and B. S. Covino: ASM Handbook Vol. 13c: Corrosion: Environments and Industries, ASM, 2006.

[20] A. Šalić and B. Zelić: Phys. Sci. Rev., 3 (2018) 1-10.

[21] J. F. Kreider et al.: Environmental engineering, in The CRC Handbook of Mechanical Engineering, Second Edition, 2005.

[22] Y. Qi, H. Luo, S. Zheng, C. Chen, Z. Lv, and M. Xiong: Int. J. Electrochem. Sci., 9 (2014) 2101-2112.

[23] A. A. Shaymaa and F. M. Hasan: in AIP Conf. Proc. 2213: 2020, 020178-1020178-6.

[24] R. W. Revie and H. H. Uhlig: Corrosion and Corrosion Control: An Introduction to Corrosion Science and Engineering, Fourth ed., John Wiley \& Sons, Inc., Canada, 2008.

[25] J. L. Wang, X. M. Zhan, Y. C. Feng, and Y. Qian: Biomed. Environ. Sci., 18 (2005) 5-8.

[26] N. Sridhar: Corrosion, 57 (2001) 221-235.

[27] S. Wang, D. Liu, N. Du, Q. Zhao, S. Liu, and J. Xiao: Int. J. Electrochem. Sci., 10 (2014) 4393-4404.

[28] A. Royani, S. Prifiharni, G. Priyotomo, J. Triwardono, and Sundjono, in IOP Conference Series: Earth and Environmental Science, 399: 2019, 1-8.

[29] K. V. Rybalka, L. A. Beketaeva, and A. D. Davydov: Russ. J. Electrochem., 54 (2018) 1284-1287.

[30] A. Ismail and N. H. Adan: Am. J. Eng. Res., 3 (2014) 64-67.

[31] K. Fujiwara, K. Yoneda, and F. Inada, "Effect of dissolved oxygen on flowaccelerated corrosion in neutral and alkaline solutions," EUROCORR 2017 Annu. Congr. Eur. Fed. Corros. 20th Int. Corros. Congr. Process Saf. Congr. 2017, pp. 1-10, 2017.

[32] U.S. Environmental Protection Agency: Quality criteria for water, Postharvest Biol. Technol., 1996.

[33] A. Sander, B. Berghult, A. Elfström Broo, E. Lind Johansson, and T. Hedberg: Corros. Sci., 38 (1996) 443-455.

\section{(c) (†) Creative Commons License}

This work is licensed under a Creative Commons Attribution 4.0 International License. 